\title{
Communicating Pain: the challenge of pain assessment in children with profound cognitive impairment.
}

\author{
Commentary for Comprehensive Child and Adolescent Nursing. January 2020 \\ Bernie Carter, Professor of Children's Nursing, Edge Hill University, UK. \\ bernie.carter@edgehill.ac.uk
}

Pain assessment is something that every nurse caring for children will need to undertake, yet it is something that is not always done effectively, and some children are more at risk of poor pain assessment than others.

Assessing typically developing children's pain can be challenging and children are susceptible to sup-optimal pain management (1-3). Many factors such as the child's gender (4), whether they are pre-verbal (5) and whether their pain is acute or chronic, can be influential. It is also clear that assessment is influenced by the perspective of who is undertaking the assessment, so self-report of pain by children can differ from that of their parents/carers or healthcare professionals, with healthcare professionals often underestimating pain (3).

Assessing pain in some groups of children, such as children with special needs (6) or children with cerebral palsy (7), can be seen as additionally challenging. Assessing the pain of children who are so profoundly cognitively impaired that they are unable to self-report their pain, as they lack the capacity to either verbally communicate or purposefully communicate their pain through other systems, is highly complex and challenging $(8,9)$. Children with profound cognitive impairment are a heterogenous group who are at particular risk of experiencing pain (10); often experiencing a higher number of nociceptive and neuropathic pain episodes compared to their healthy peers and sometimes experiencing significant daily pain that impacts on their lives $(1,11,12)$. This pain arises from the interplay between their underlying condition and their range of comorbidities; this complicates both assessment and management (13).

Children with profound cognitive impairment are therefore completely reliant on their parents/carers, and on their healthcare professionals for effective assessment and management of their pain. Studies show that, despite robust and validated tools being available (14), many healthcare professionals lack confidence in their ability to assess and manage pain in this group of children $(9,15)$.

However, whereas healthcare professionals acquire their skill set and knowledge through a reasonably established curriculum (lectures, books, learning from more experienced clinicians) and across a range of children, parents acquire knowledge through experiential learning about their own child and with little professional input $(8,9)$. Although studies have demonstrated that parents of children with profound cognitive impairment often develop knowledge and skills experientially $(8,15)$ and are generally accurate in assessing their child's pain (10), other evidence shows that some may underestimate the intensity of their child's pain (16).

This informal curriculum in which parents learn from their child can work well until something happens which challenges their knowledge, skill set and confidence. This may result from their child's existing pain increasing in intensity or a new source of pain developing. In these circumstances the situation can overwhelm the parents'/carers' resources and they turn to healthcare professionals for additional expertise, insight and intervention (8). However, confronted with the complexity of the child's, often unique, health care needs and idiosyncratic behaviours, healthcare professionals may experience uncertainty as they perceive their usual 'road map' for pain assessment to be inadequate (9). 'Teasing out' pain cues and unravelling whether the child is in pain, what is causing it, and how best to treat the pain, is not simple. In such situations, collaborative working between the parents/carers and healthcare 
professionals, based on mutual respect and acknowledgement of each other's expertise and potential contribution, is likely to create optimal circumstances for effective pain assessment and subsequent management. However, this may not always happen.

Having talked to many parents/carers within practice and during research interviews, it is clear that they value healthcare professionals who pause and listen to what they are saying and do not dismiss their ideas, concerns or 'gut feelings'. They value healthcare professionals who respect their unique knowledge about their child but do not expect them to know everything. They appreciate healthcare professionals who accept that trying to put their child's pain into words is tricky and that it can be a struggle to find a meaningful way of communicating their child's pain.

Nurses working as clinicians, managers, educators, leaders and researchers all have an obligation to ensure that they contribute effectively in whatever way they can to ensuring that pain assessment and management is optimal. Although the existing evidence-base about pain assessment in children with profound cognitive impairment is relatively small, it is robust and it offers clear direction. Despite none being ideal, we should be assessing their pain using specific, validated tools $(10,14)$ such as the Paediatric Pain Profile(17), the revised-Face, Legs, Activity, Cry, Consolability (r-FLACC) tool (18), and the Non-Communicating Children's Pain ChecklistRevised (NCCPC-R)(19). All of this needs to be done in dialogue with the child's parents/carers.

In my role as a researcher with strong links to clinical practice, and with years of listening to both parents and professionals wanting to improve pain assessment, I realized that one way I could help was to find new ways of disseminating research findings. I wanted to reach out and inform parents and healthcare professionals about the issue and I wanted to do this in a collaborative way. On this dissemination journey I have been involved in working with dancers who choreographed my findings. This work has been performed in public. I have also worked with a writer/artist and director to create an audio-visual installation which has been performed in a theatre and at science festivals. This installation has been adapted for presentation at conferences. I have also worked with illustrators and animators to create a freely available resource, 'Communicating Lily's Pain'.

'Communicating Lily's Pain' includes an animation which is now online https://www.edgehill.ac.uk/communicatinglilys pain/. Work is ongoing to create information sheets and teaching materials. The whole of the animation is based on parents' words, and parents and professionals were involved throughout its creation. In two minutes, this animation distills the essence of much of my own pain research and reflects the core messages from other pain researchers. 'Communicating Lily's Pain' aims to inform parents of children with profound cognitive impairment and professionals working with this diverse group of children, as well as informing the wider public. It aims to act as a trigger for conversations; to help parents feel less alone and to provide professionals with insight into what parents need from them. In its own small way, I hope that this resource will stimulate conversations about pain, encourage more critical thinking, and help bring about change.

\section{References}

1. Carter B, Simons J. Stories of Children's Pain: Linking Evidence to Practice. Los Angeles: SAGE; 2014.

2. Twycross A. Children's nurses' post-operative pain management practices: An observational study. International Journal of Nursing Studies. 2007;44:869-81 doi: 10.1016/j.ijnurstu.2006.03.010 [published Online. 
3. Brudvik C, Moutte S-D, Baste V, Morken T. A comparison of pain assessment by physicians, parents and children in an outpatient setting. Emergency Medicine Journal. 2017;34:138-44 doi:

10.1136/emermed-2016-205825 [published Online.

4. Earp BD, Monrad JT, LaFrance M, Bargh JA, Cohen LL, Richeson JA. Gender Bias in Pediatric Pain Assessment. Journal of pediatric psychology 2019;44:12 doi: 10.1093/jpepsy/jsy104 [published Online.

5. Andersen RD, Nakstad B, Jylli L, et al. The Complexities of Nurses' Pain Assessment in

Hospitalized Preverbal Children. Pain Management Nursing. 2019;20:337-44 doi:

10.1016/j.pmn.2018.11.060 [published Online.

6. Quinn BL, Seibold E, Hayman L. Pain Assessment in Children With Special Needs: A Review of the Literature. Exceptional Children. 2015;82:44-57 doi: 10.1177/0014402915585480 [published Online.

7. Riquelme I, Pades Jiménez A, Montoya P. Parents and Physiotherapists Recognition of NonVerbal Communication of Pain in Individuals with Cerebral Palsy. Health Communication. 2018;33:1448-53 doi: 10.1080/10410236.2017.1358243 [published Online.

8. Carter B, Arnott J, Simons J, Bray L. Developing a Sense of Knowing and Acquiring the Skills to Manage Pain in Children with Profound Cognitive Impairments: Mothers' Perspectives. Pain Res Manag. 2017;2017:2514920 doi: 10.1155/2017/2514920 [published Online First: 2017/03/26].

9. Carter B, Simons J, Bray L, Arnott J. Navigating Uncertainty: Health Professionals' Knowledge, Skill, and Confidence in Assessing and Managing Pain in Children with Profound Cognitive Impairment. Pain Res Manag. 2016;2016:8617182 doi: 10.1155/2016/8617182 [published Online First: 2016/12/21].

10. Cascella M, Bimonte S, Saettini F, Muzio MR. The challenge of pain assessment in children with cognitive disabilities: Features and clinical applicability of different observational tools. Journal of Paediatrics and Child Health. 2019;55:129-35 doi: 10.1111/jpc.14230 [published Online.

11. Zernikow B, Wager J, Hechler T, et al. Characteristics of highly impaired children with severe chronic pain: a 5-year retrospective study on 2249 pediatric pain patients. BMC pediatrics. 2012;12:54- doi: 10.1186/1471-2431-12-54 [published Online.

12. Breau LM, Camfield CS, McGrath PJ, Finley GA. The Incidence of Pain in Children With Severe Cognitive Impairments. Archives of Pediatrics \& Adolescent Medicine. 2003;157:1219-26 doi: 10.1001/archpedi.157.12.1219 [published Online.

13. Bottos S, Chambers CT. The epidemiology of pain in developmental disabilities. In: Oberlander TF, Symons FJ, eds. Pain in Children \& Adults with Developmental Disabilities. Baltimore: Maryland Paul H Brookes Publishing 2006:67-87.

14. Association of Paediatric Anaesthetists of Great B, Ireland. Good Practice in Postoperative and Procedural Pain Management, 2nd Edition. Pediatric Anesthesia. 2012;22:1-79 doi: 10.1111/j.14609592.2012.03838.x [published Online.

15. Hunt A, Mastroyannopoulou K, Goldman A, Seers K. Not knowing - the problem of pain in children with severe neurological impairment. International Journal of Nursing Studies. 2003;40:171-83 doi: 10.1016/S0020-7489(02)00058-5 [published Online.

16. Stallard P, Williams L, Velleman R, Lenton S, McGrath PJ. Behaviors identified by caregivers to detect pain in noncommunicating children. Journal of pediatric psychology. 2002;27:209-14 doi: 10.1093/jpepsy/27.2.209 [published Online.

17. Hunt A, Goldman A, Seers K, et al. Clinical validation of the Paediatric Pain Profile. Developmental Medicine and Child Neurology. 2004;46:9-18 doi: 10.1017/S0012162204000039 [published Online.

18. Malviya S, Voepel-Lewis T, Burke C, Merkel S, Tait AR. The revised FLACC observational pain tool: improved reliability and validity for pain assessment in children with cognitive impairment. Pediatric Anesthesia. 2006;16:258-65 doi: 10.1111/j.1460-9592.2005.01773.x [published Online.

19. Breau LM, Finley GA, McGrath PJ, Camfield CS. Validation of the Non-communicating Children's Pain Checklist-Postoperative Version. Anesthesiology. 2002;96:528-35 doi: 10.1097/00000542200203000-00004 [published Online. 